\title{
Nova dramaturgia na Grã-Bretanha Como definir o teatro contemporâneo?
}

\section{Aleks Sierz}

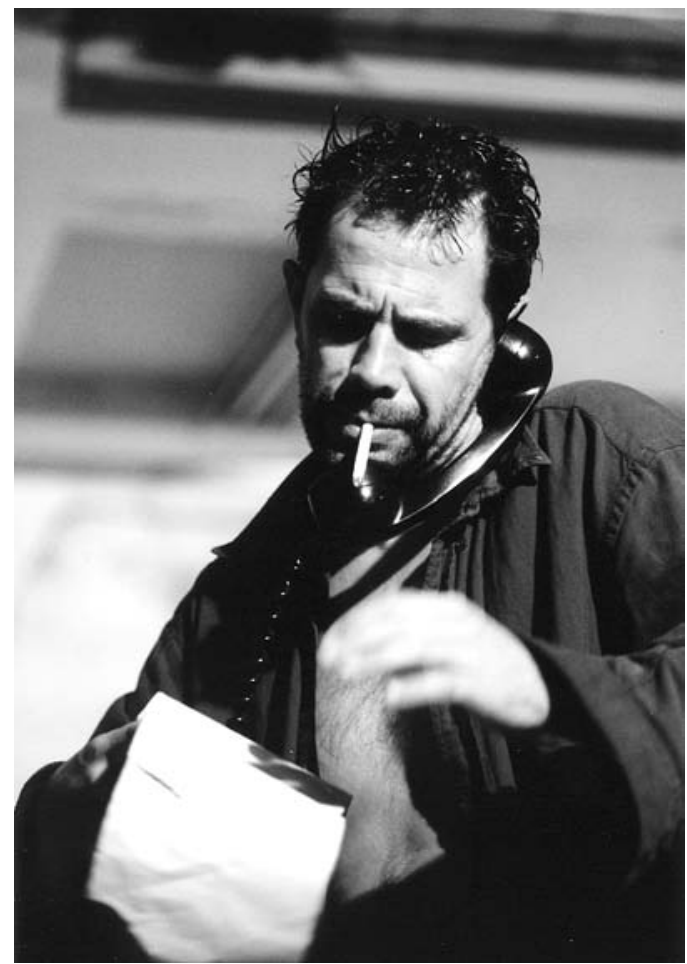

Gostaria de começar por representar uma peça. Não se preocupem, é uma peça muito breve. Trata-se, na verdade, de uma paródia de Sarah Kane. Escrita por um dramaturgo irlandês chamado Chris Lee. Por isso, aqui têm, na integra, a versão de Chris Lee de uma peça muito breve de Sarah Kane - acrescente-se, já agora, que se trata de uma representação ilegal, mas estou certo de que gostarão de saber que é também a estreia portuguesa desta peça. Chama-se Esmagada (Crushed):

\section{Aparece uma cabeça}

CABEÇA: Foda-se. Cona. Foda-se. Na cona foda-se na cona na cona foda-se.

Entra um homem com um chapéu de baseball. Inclina-se e beija a cabeça. Levanta-se. Esmaga a cabeça com o bastão de baseball. Pousa o bastão. Baixa as calças e urina sobre a cabeça. Espera. Defeca sobre a cabeça. Espera. Masturba-se e ejacula sobre a cabeça. Onde antes estava a cabeça, aparece subitamente uma árvore. ÁRVORE: Conheci finalmente o amor.

Subitamente, a árvore explode. 0 homem explode. 0 teatro explode. 0 mundo explode.

Fodam-se vocês todos.

Adeus.

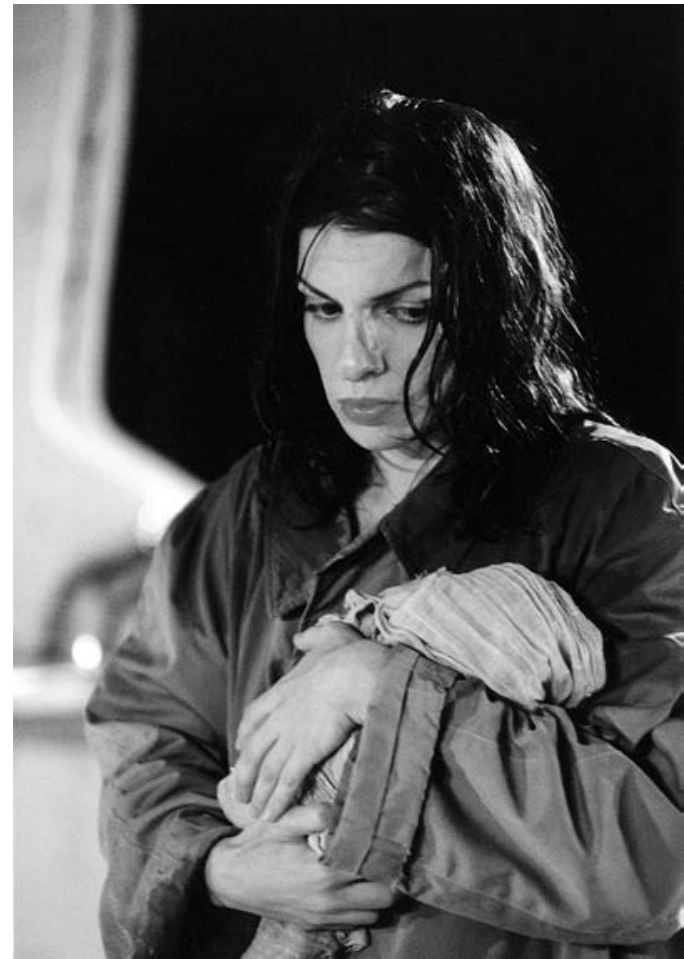

Claro que tenho a consciência - especialmente na presença de tantos críticos distintos - que esta paródia não é perfeita. Kane nunca teria escrito "defecar" quando aquilo que queria dizer era "cagar", ou "urinar" quando se referia a "mijar", mas ainda assim parece-me que, em termos da sua sensibilidade, a peça de Chris Lee transmite na perfeição o tom daquilo a que uma vez chamei o "teatro in-yerface" (2001). A linguagem explícita, a insistência no sexo e na violência, a imagética intensa, e o tema central do amor romântico, está tudo aqui - expresso como uma espécie de facsimile verosímil do estilo característico de Kane.

0 simples facto de uma tal paródia ser possivel sugere duas coisas: que todos reconhecemos a voz individual de um escritor e que todos temos alguma noção do que é o teatro contemporâneo. Mas será mesmo assim?

Gostaria de aproveitar esta comunicação para explorar a questão do que é o teatro contemporâneo. E gostaria de começar por citar uma peça muito diferente de qualquer coisa que Sarah Kane possa ter escrito. Refiro-me à premiada peça de Alan Bennet, The History Boys (2004). Como saberão, The History Boys é sobre um sujeito chamado Irwin, um professor de história que tenta preparar
Ruinas,

de Sarah Kane,

enc. Jorge Silva Melo e

Paulo Claro,

Artistas Unidos, 2000

(< João Saboga:

$>$ Carla Bolito),

fot. Jorge Gonçalves. 


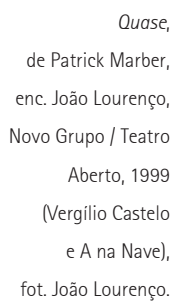

Todas as traduções

são da minha

responsabilidade, excepto quando

diversamente

assinalado. N.T.

2 o tempo e a ira

corresponde ao título da tradução de José

Palla e Carmo utilizada

nos espectáculos do

Teatro Experimental do

Porto, em 1967,

e do Teatro

Experimental de

Cascais, em 1968. Mais

recentemente, em

1996, a Companhia

Teatral do Chiado

utilizou uma nova tradução, de Gustavo Rubim, com o titulo Dá raiva olhar para trás.

N.T. uma turma de alunos adolescentes para os seus exames finais, encorajando-os a fazer interpretações imaginativas e originais da história. A dada altura, sugere-Ihes que eles se devem distanciar do presente. Diz ele:

\footnotetext{
Distanciem-se. A nossa perspectiva do passado altera-se. Olhando para trás, aquilo que encontramos imediatamente à nossa frente é terreno morto. Não o vemos e porque não o vemos isso significa que não há nenhum periodo tão remoto como o passado recente. Uma das tarefas do historiador é antecipar aquela que poderá ser a nossa perspectiva desse periodo. (Bennet 2004: 74) ${ }^{1}$
}

Isto levanta a questão de sabermos se é alguma vez possivel apreender aquilo que nos é contemporâneo: se é verdade que "não há nenhum período tão remoto como o passado recente", como é que poderemos alterar a nossa perspectiva e conseguir uma visão mais clara desse "período remoto"?

Um modo de o fazermos, na minha opinião, é reformulando a questão. Em lugar de tentarmos imediatamente compreender o contemporâneo, talvez a melhor maneira seja a de perguntar: o que é a nova dramaturgia?

Na Grã-Bretanha, a ideia de nova dramaturgia constitui uma presença imensamente poderosa no teatro: onde quer que se vá, somos apresentados a "novos dramaturgos"e podemos ver peças que são exemplos da "nova dramaturgia". Por todo o lado existem "festivais de nova dramaturgia". Existe, na verdade, um verdadeiro dilúvio do novo.

Mas o que é a "nova dramaturgia"? Trata-se, primeiro, de uma ideia muito britânica - nos Estados Unidos da América, poucos são aqueles que alguma vez ouviram falar de "nova dramaturgia"; na Europa, só é esporadicamente vislumbrada. Nesses países, existem peças antigas e peças novas, mas a "nova dramaturgia" tem um estatuto reduzido e nenhuma história. Trata-se
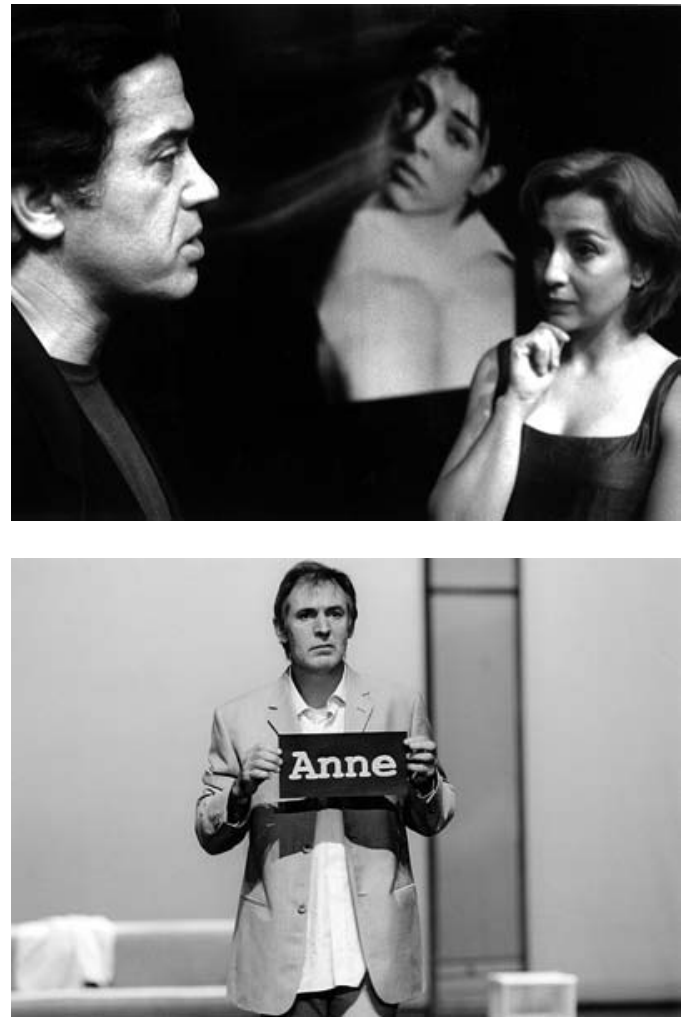

de um fenómeno muito britânico. Mas então o que é?

Uma definição de nova dramaturgia requer, no mínimo, três elementos, a saber:

1) História. Nova dramaturgia designa o conjunto de peças escritas na "Grande Tradição" da "nova dramaturgia" iniciada pelo Royal Court em 1956 com 0 tempo e a ira (Look Back in Anger), de John Osborne ${ }^{2}$. É esse o quadro histórico. Esse foi o momento em que a ideia de "novo" se tornou gradualmente sinónimo de "original" e, dai, de "bom". A ideia de novidade, de não ter sido visto antes, tornou-se uma verdadeira virtude (cf. Chambers / Prior 1987: 132). E no Royal Court, durante os anos sessenta, a ideia de "novo" acabou por corresponder a textos significativos, dotados de imediatismo e de relevância. Em resumo, a nova dramaturgia tornou-se sinónimo de teatro contemporâneo.

2) Dramaturgos. Nova dramaturgia designa o conjunto de peças compostas por escritores que encaram o papel do dramaturgo como central à criação teatral. Muitas vezes, esses novos escritores são jovens, habitualmente com vinte e poucos anos, e, na verdade, o teatro britânico não tem sido mais bem sucedido do que qualquer outro nos seus esforços de escapar ao culto da juventude. Sarah Kane, por exemplo, tinha 23 anos quando a peça Ruinas foi pela primeira vez levada à cena. Nova dramaturgia corresponde habitualmente ao trabalho inicial de jovens dramaturgos, mas a sua idade é menos importante do que o facto de se estarem a estrear. No Festival de Novas Peças de Londres, em 1999, por exemplo, 10 dos 12 "novos dramaturgos" tinham mais de 40 anos. E isso não importava - eram todos novos dramaturgos.

3) Instituições. Nova dramaturgia designa o conjunto de peças escritas para teatros especializados subsidiados pelo Estado que se mostram mais interessados na criação artística do que no comércio teatral. Começando com a experiência de George Devine na direcção do Royal Court, 


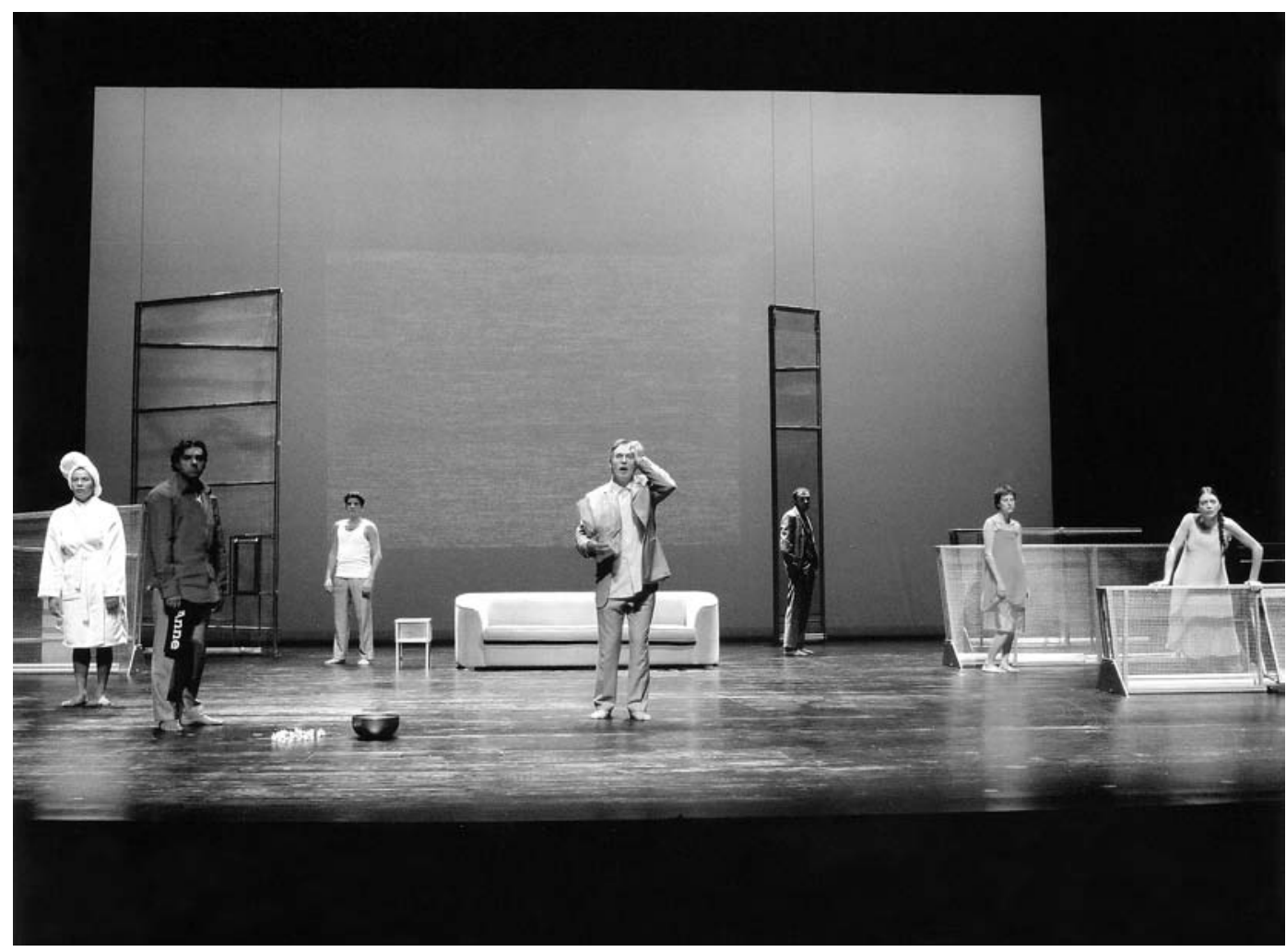

a nova dramaturgia é habitualmente encarada como tendo sido criada em oposição ao teatro comercial. 0 grito de guerra de Devine, a sua famosa reivindicação do "direito a falhar", e a necessidade associada de experimentar, tornou-se o seu mito fundador, do mesmo modo que o apoio financeiro do Estado se afirmou como o seu correlato económico. Não tinham de depender do mercado para serem bem sucedidos - e muitos clássicos modernos, tais como as primeiras obras de John Arden, foram originalmente fracassos comerciais. Actualmente, a nova dramaturgia é uma indústria como os seus teatros especializados. (Às companhias instaladas no Royal Court, no Bush, no Hampstead e no Soho Theatre em Londres acrescentam-se ainda alguns centros regionais, como o Traverse em Edimburgo e o The Door em Birmingham.)

Se esta definição de nova dramaturgia assegura uma explicação histórica, económica e social desta tradição teatral britânica e consegue mostrar a importância deste fenómeno cultural, ela acaba, contudo, por contornar a questão muito mais interessante, que se prende com a estética: com que é que se parece um texto da "nova dramaturgia"? Em que estilo é que é escrito? E que temas é que aborda?

\section{Estilo contemporâneo}

A expressão "teatro contemporâneo" designa o conjunto de peças escritas num estilo contemporâneo. Na paródia de Sarah Kane apresentada no início desta intervenção, torna-se muito claro que o seu estilo linguistico é instantaneamente reconhecivel como sendo a voz de hoje. A nova dramaturgia nos anos noventa transformou a linguagem do teatro britânico, tornando-o mais directo, mais cru e explícito. Não só introduziu um novo vocabulário dramático, como também levou o teatro a empenhar-se, de forma mais agressiva, na reacção e nas sensações do público.
Quando, numa famosa cena de Ruinas, Sarah Kane usou a palavra "cona" onze vezes de seguida, ela estava não só a fazer explodir um tabu feminista, mas também, ao mesmo tempo, a denunciar uma visão da psicologia masculina e a explorar o poder expressivo do palavrão contemporâneo.

Mas um sentido do estilo contemporâneo não é só uma questão de palavras injuriosas e de trocas rápidas de palavras sob a forma de falas breves. Um sentimento de "agoridade" pode também ser transmitido através de ideias e da sensibilidade. Quando, em Shopping and Fucking, Mark Ravenhill põe Robbie a dizer: "Penso que todos nós precisamos de histórias, inventamos histórias para conseguirmos aguentar-nos". Esta simples afirmação recorda não só as teorias de Jean-François Lyotard, como ecoa também a Geração X, do romancista norte-americano Douglas Copeland, publicado cinco anos antes da estreia da peça de Ravenhill. Nesse livro, Claire diz: "Ora as nossas vidas se tornam histórias, ou então não há maneira de as vivermos". Ecos como estes ajudam a tornar a linguagem e as ideias destas peças contemporâneas no domínio do estilo e dos sentimentos que exprimem.

Mas também existem perigos em se ser demasiado contemporâneo. Podemos chamar-lhes a praga do agora. E o modo mais fácil de se garantir que uma peça irá tornar-se datada muito rapidamente é enchê-la de referências contemporâneas. Por exemplo, quando em Quase (Closer), de Patrick Marber, Alice pede emprestado o telefone móvel de Dan, no texto pode ler-se: "Ela puxa a antena com os dentes". Pouco tempo após a estreia da peça, o típico telefone móvel deixou de precisar de uma antena. Razão pela qual numa edição subsequente da peça de Marber, em 2004, esta indicação cénica foi cortada. No espaço de cinco anos, já estava completamente desactualizada. Envelhecida. 


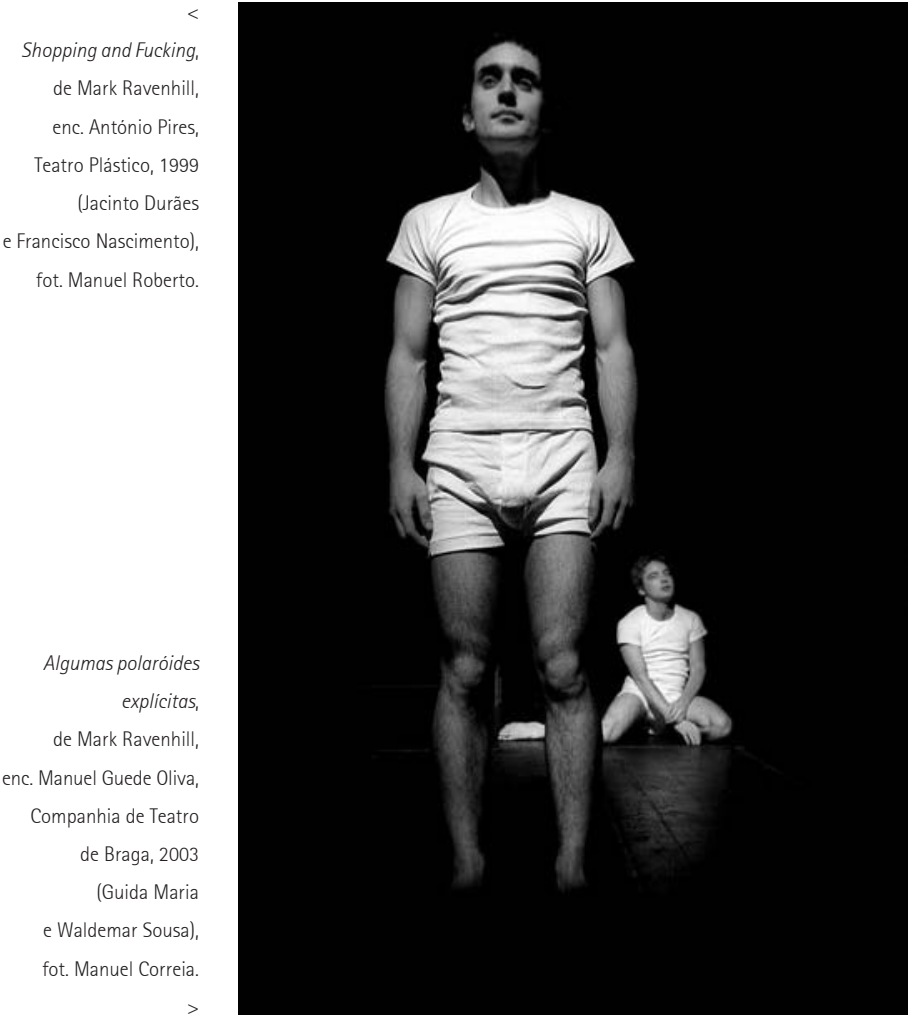

Questões contemporâneas

A expressão "teatro contemporâneo" designa o conjunto de peças escritas sobre questões contemporâneas. Regressando à paródia de Sarah Kane, é possivel argumentar que aquela pequena peça aborda o problema actual da violência juvenil e sugere as mais vastas questões do poder nuclear e dos impulsos auto-destrutivos da humanidade.

Ruínas, uma peça real de Sarah Kane, é sobre questões contemporâneas como o abuso sexual, a crise da masculinidade e as guerras de genocídio. Desde o $11 \mathrm{de}$ Setembro, claro, a questão contemporânea mais importante vem sendo a Guerra ao Terror. Neste caso, por vezes, até o naturalismo pode ser visionário.

Lembro-me do espectáculo para a imprensa de Redundante (Redundant), de Leo Butler, no Royal Court, em Setembro de 2001. Tratava-se de uma peça num estilo realista clássico, localizada numa espécie de bairro social, atravessada por um uivo de raiva bem familiar. Mas também encerrava um momento visionário, quando, a dada altura, a avó se voltava para o resto do elenco, proclamando:

\footnotetext{
Alguém devia bombardear a porra deste país. Talvez isso nos acordasse. 0 Saddam Hussein ou qualquer outro. O IRA, ou a porra daquele, como é que ele se chama, o Bin Laden. Ele seria capaz. De lançar umas quantas toneladas de antrax. E de nos ensinar realmente o que significa sofrer. (Butler 2001)
}

Naquele espectáculo de estreia para a imprensa, a frase em que se referia Bin Laden foi cortada - e não era difícil de perceber porquê: a data era 12 de Setembro de 2001. 0 dia a seguir ao 11 de Setembro. Mas aquele discurso mostra bem como os escritores podem estabelecer ligações com acontecimentos globais quando soltam a trela das suas imaginações.

Do mesmo modo, algumas das peças mais provocadoras sobre a Guerra ao Terror são não as sátiras sensacionalistas

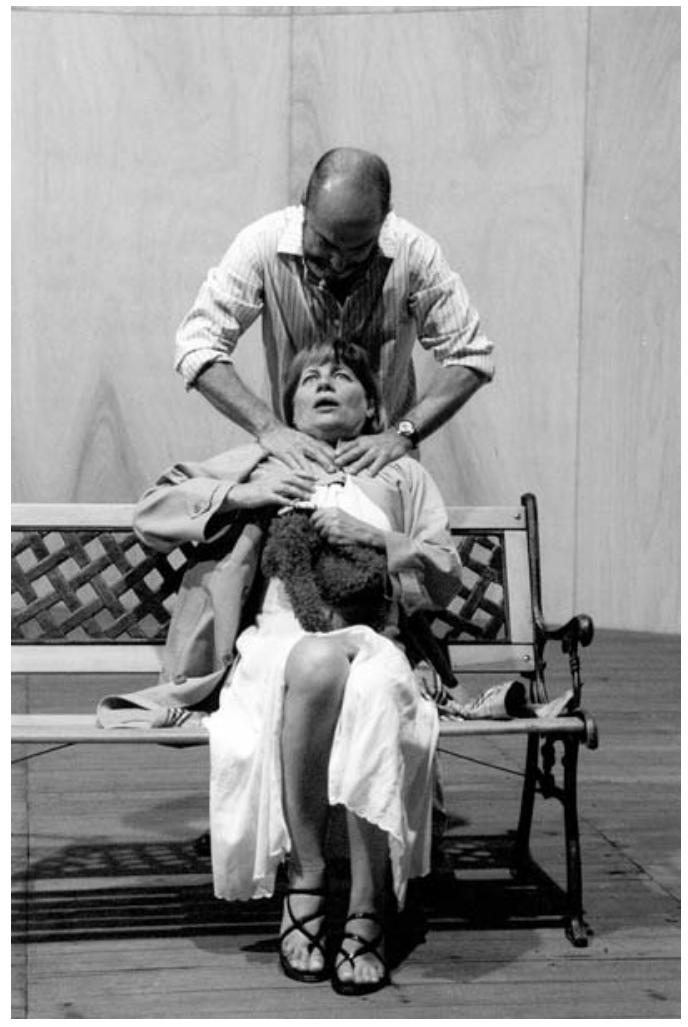

que pregam aos convertidos, mas as reescritas de antigas tragédias gregas. Por exemplo, Ternas e cruéis (Cruel and Tender), de Martin Crimp, uma adaptação livre de As Traquínias, de Sófocles, diz-nos mais sobre o espirito da nossa época do que muitas das recentes caricaturas de Blair e de Bush.

Em Ternas e cruéis, Crimp fala-nos do medo do terror. Se pedissemos a um dramaturgo menor uma imagem da ameaça terrorista, ele seria capaz de sugerir uma imagem banal, talvez a de um jovem de tez escura com uma mochila, a entrar no sistema do metropolitano de Londres. Crimp arrisca um salto muito mais imaginativo. Escreve ele:

Cada sinal de vapor num céu frio / é uma ameaça / cada criança sem
sapatos / parada num posto de controlo [é uma ameaça] (...) e até
mesmo o candeeiro na mesinha de cabeceira / até mesmo o filamento espiralado dentro da lâmpada / é uma ameaça. (Crimp 2004: 58)

Gosto particularmente desta última imagem: o candeeiro da mesinha de cabeceira é a testemunha das nossas actividades mais intimas e, ao convocá-lo, Crimp mostranos como o terror conseguiu penetrar no coração da consciência ocidental. Além disso, como acontece com toda a grande arte, este tipo de imagens alteram o modo como encaramos a nossa vida quotidiana. Ao escutarmos este passo, emerge a sensação de que uma lâmpada, 0 mais doméstico dos objectos, é na verdade uma ameaça - uma bomba à espera de explodir

\section{Provocações contemporâneas}

A expressão "teatro contemporâneo" designa o conjunto de peças que desafiam ou provocam o seu público.

Regressando à paródia de Sarah Kane com que iniciei esta intervenção: existe algo inerentemente provocador e perturbador na sua agressividade e na sua determinação em esfregar a cara dos espectadores na merda. Existem 


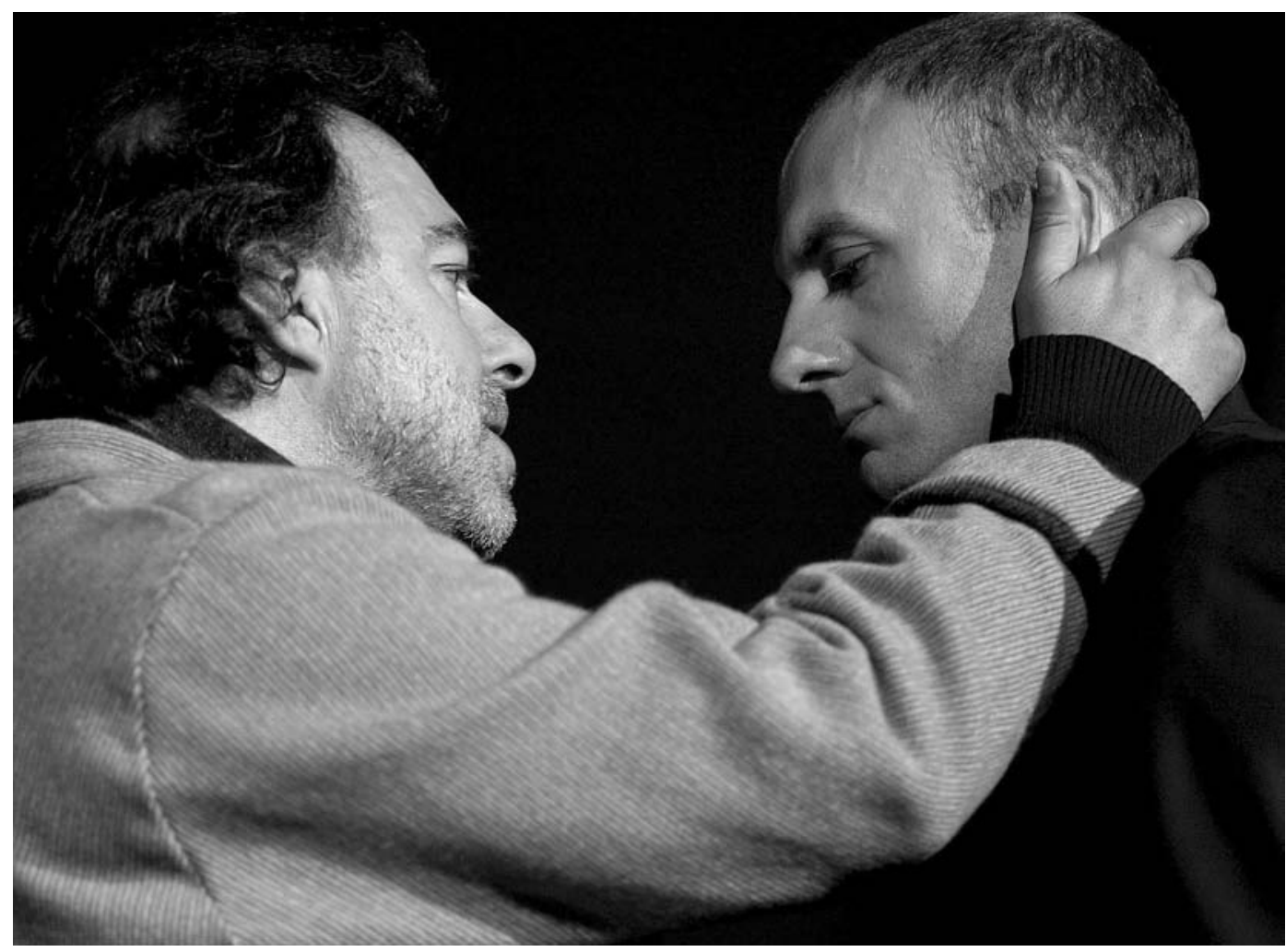

algumas peças, com destaque para as de Sarah Kane e de Mark Ravenhill, cuja linguagem, imagética cénica e ideias centrais se apresentam como intrinsecamente provocadoras.

Mas algumas ideias são mais subtilmente provocadoras e controversas. Shopping and Fucking, de Mark Ravenhill, por exemplo, é sobre o consumismo e o individualismo, sobre a dependência das drogas e o valor do dinheiro, 0 sexo alienado e o abuso sexual. Mas o aspecto mais contemporâneo da obra de Ravenhill não são, parece-me, as referências tecnológicas a coisas como a Internet ou Bill Gates que povoam algumas das suas peças. De modo muito mais profundo, as peças de Ravenhill sugerem uma sensibilidade (isto é, uma união de sentimentos e de ideias) que não seriam possíveis, por exemplo, nos anos oitenta. Um bom exemplo disto é a cena 11 de Algumas polaróides explícitas (Some Explicit Polaroids). Nesta cena, Nick, o velho esquerdista, e Jonathan, o novo empresário, discutem a sua nostalgia pelos dias da Guerra Fria. Nas palavras de Jonathan: "A nostalgia é uma puta duma cabra esquisita, não é? Mas a verdade é que, neste preciso instante, me sinto bastante nostálgico em relação ao tempo que passámos juntos)" (Ravenhill 2003: 90). Em momentos como este, a grande tradição da peça sobre o "estado-danação" encontra-se com a realidade contemporânea de uma economia globalizada e a expressão da nostalgia parece resumir um sentido distintamente contemporâneo de deriva, incerteza e confusão. Politicamente, poucos teriam sido capazes de escrever deste modo antes da queda do muro de Berlim, em 1989.

Mas a obra de Ravenhill afirma-se como contemporânea ainda de um outro modo. Refiro-me, é claro, ao tema dos pais ausentes nas suas peças. Em obras como Shopping and Fucking, Fausto morreu (Faust Is Dead) e Mala (Handbag), encontramos não só a ausência de bons pais, como além disso o seu lugar foi preenchido por pais maus e abusadores, como é o caso de Brian, o brutal traficante de droga, de Alain, o filósofo anarquista, ou do conjunto de homens indiferentes em Mala. Naturalmente, a ausência de figuras paternas não é por si só um sinal de contemporaneidade; afinal de contas, Hamlet é uma peça com um pai bom ausente e um pai substituto abusador. 0 que torna a ausência do pai nas peças Ravenhill em algo de tão contemporâneo é o modo como isso funciona como um símbolo da ausência de um Estado mais paternalista. Na era pós-Thatcher, não foram só os pais, individualmente falando, que desapareceram, mas também o Estado Providência que tomava conta dos seus cidadãos. Isto faz dos pais ausentes na obra de Ravenhill não só um tema que tresanda a contemporaneidade, mas também uma afirmação política.

\section{Forma contemporânea}

A expressão "teatro contemporâneo" designa o conjunto de peças que desafiam a forma teatral. Na já muitas vezes referida paródia de Sarah Kane, é possivel afirmar que o modo como o texto se afasta da forma da tradicional "peça-bem-feita" é um sinal directo da sua contemporaneidade. Com isto em mente, talvez que uma melhor definição de teatro contemporâneo seja aquela que se liberta do conteúdo das peças e olha antes para a sua forma. Talvez que a peça verdadeiramente contemporânea seja aquela que empenhadamente desafia as velhas formas do drama e exprime a sua "agoridade" através de uma atitude experimental relativamente à estrutura. Por outras palavras, $\dot{A}$ espera de Godot em lugar de 0 tempo e a ira; ou se preferirem, 0 animador (The Entertainer) em lugar de Epitáfio por George Dillon (Epitaph for George Dillon).

Elyse Dodgson, a responsável pelo Departamento internacional do Royal Court, disse-me uma vez: "Procuramos trabalhos que sejam originais, acutilantes, 
provocadores e contemporâneos, mas nunca falamos da sua forma - isso cabe a cada um dos escritores.

Desencorajamos ostensivamente peças históricas e adaptações".

Obviamente, todos conseguimos lembrar-nos de peças notáveis que arriscam experiências formais, desde 4:48 Psicose (4:48 Psychosis), de Sarah Kane, até Piscina sem água (Pool No Water), de Ravenhill, ou de (A)tentados (Attempts on Her Life), de Martin Crimp, até quase todas as peças de Caryl Churchill. Mas porque é que deviamos pensar nisto como especialmente contemporâneo? Não será antes uma espécie de nostalgia estética pelos velhos tempos do modernismo teatral, quando - como Martin Crimp uma vez satiricamente sugeriu em (A)tentados dominava "o princípio de que a forma obedece à função"? (Crimp 2000: 142). Talvez. Mas eu penso que existe uma outra razão pela qual as experiências com a estrutura se apresentam como tão entusiasmantes e tão contemporâneas. Porque o facto é que sempre que um escritor faz experiências com a forma ele desafia a estética dominante do naturalismo (pelo menos, na Grã-Bretanha) e ao fazê-lo anuncia aos espectadores que aquilo que eles estão a ver não é a vida real, mas teatro. Quando isto acontece, o escritor chama a atenção para o facto de 0 teatro ser uma espécie de ficção.

Porque é que isto é importante? Bem, porque me parece que a ficção dispõe de certos poderes e características que a vida não tem. A ficção é, por exemplo um lugar de sonho, de imaginação e de magia. É um lugar no qual os conflitos sociais do mundo real, que muitas vezes teimosamente desafiam qualquer solução, podem ser resolvidos num mundo imaginativo. È desse modo que Sarah Kane cria em Ruinas um conflito irresolúvel entre lan e Cate, um homem e uma mulher, acabando no final por resolver magicamente as tensões entre eles. Em Shopping and Fucking, Mark Ravenhill acaba por transformar uma peça de realismo duro num conto de fadas urbano: o traficante de droga devolve o dinheiro aos jovens. Imaginem isso a acontecer no mundo real. Só por magia. Em (A)tentados, Martin Crimp consegue o impossivel: cria uma personagem ausente que tanto pode ser uma única mulher como todas as mulheres, e as duas coisas ao mesmo tempo; este é o poder da ficção.

Por último, um outro modo através do qual uma qualquer ficção anuncia a sua contemporaneidade é provocando a divisão de opiniões entre os críticos e o seu público. Os exemplos referidos atrás fizeram justamente isso. Quando há conflito, há discussão; quando há divisão, há o contemporâneo. Talvez que as peças mais contemporâneas sejam aquelas que conseguem fazer duas coisas: chamar a atenção e, ao mesmo tempo, questionar a sua própria contemporaneidade. Como, satiricamente, escreve Martin Crimp em (A)tentados: "É teatro - exacto - para um mundo no qual o próprio teatro morreu" (Crimp 2000: 192).

\section{Referências bibliográficas}

BENNET, Alan (2004), The History Boys, London, Faber and Faber BUTLER, Leo (2001), Redundant, London, Methuen.

CHAMBERS, Colin / PRIOR, Mike (1987), Playwrights' Progress: Patterns of Postwar British Drama, Oxford, Amber Lane Press.

CRIMP, Martin (2000), Peça com repetições / (A)tentados, trad. Paulo Eduardo Carvalho, Porto, Campo das Letras.

-- (2004), Cruel and Tender, London, Faber and Faber.

KANE, Sarah (2001), Teatro completo, trad. Pedro Marques, Porto, Campo das Letras.

MARBER, Patrick (2005), Quase, trad. João Lourenço e Vera San Payo de Lemos, Lisboa, Relógio D'Água.

RAVENHILL, Mark (2003), Algumas polaróides explicitas, trad. Regina Guimarães, Braga, Companhia de Teatro de Braga.

SIERZ, Aleks (2001), In-Yer-Face Theatre: British Drama Today, London, Faber and Faber.

Tradução de Paulo Eduardo Carvalho 